\title{
DCZ0014, A Novel Compound in the Therapy of Diffuse Large B-Cell Lymphoma via the B Cell Receptor Signaling Pathway
}

\section{Shuaikang Chang}

Shanghai Tenth People's Hospital

Bo Li

Shanghai Institute of Materia Medica Chinese Academy of Sciences

Yingcong Wang

Shanghai Tenth People's Hospital

Qilin Feng

Shanghai Tenth People's Hospital

\section{Zhijian Xu}

Shanghai Institute of Materia Medica Chinese Academy of Sciences

Yi Tao

Shanghai Tenth People's Hospital

\section{Rong Wei}

Shanghai Tenth People's Hospital

Yumeng Lu

Shanghai Tenth People's Hospital

\section{Yong Zhang}

Shanghai Institute of Materia Medica Chinese Academy of Sciences

\section{Yongsheng Xie}

Shanghai Tenth People's Hospital

\section{Weiming Lai}

Shanghai Tenth People's Hospital

\section{Xiaosong Wu}

Shanghai Tenth People's Hospital

\section{Weiliang Zhu}

Shanghai Institute of Materia Medica Chinese Academy of Sciences

Jumei Shi ( $\nabla$ shijumei@tongji.edu.cn )

Shanghai Tenth People's Hospital

\section{Research}


Keywords: Diffuse Large B Cell Lymphoma, DCZ0014, Apoptosis, Lyn, Syk

Posted Date: August 1st, 2020

DOI: https://doi.org/10.21203/rs.3.rs-48447/v1

License: (1) (1) This work is licensed under a Creative Commons Attribution 4.0 International License. Read Full License

Version of Record: A version of this preprint was published at Neoplasia on January 1st, 2022. See the published version at https://doi.org/10.1016/j.neo.2021.12.001. 


\section{Abstract}

Background: Diffuse large B cell lymphoma (DLBCL) is a clinical and genetically heterogeneous lymphoid malignancy. Although the R-CHOP (rituximab plus cyclophosphamide, vincristine, doxorubicin, and prednisone) treatment can improve the survival rate of patients with DLBCL. However, more than $30 \%$ of patients exhibit treatment failure, relapse, or refractory disease. Therefore, novel drugs or targeted therapies are needed to improve the overall survival of patients with DLBCL. The compound DCZ0014 is a novel chemical similar to berberine, obtained by drug design and organic synthesis.

Methods: The anti-DLBCL activity of DCZ0014 were investigated using assays of colony formation, CCK8, TUNEL assay, EdU assay, cell cycle analysis, flow cytometry analysis, MMP analysis, Western blotting, immunohistochemistry and xenograft tumour model. Overexpression and knockdown of lyn in DLBCL cells was constructed with the small interfering RNAs or plasmid. The student's t-test was performed to the statistical analysis.

Results: We found that DCZ0014 significantly inhibited the proliferation and activity of DLBCL cells, reduced the formation of their clones, and induced cell apoptosis. Following treatment with DCZ0014, DLBCL cells accumulated in G0/G1-phase of the cell cycle and showed decreased mitochondrial membrane potential. Additionally, DCZ0014 significantly inhibited DNA synthesis, enhanced DNA damage in DLBCL cells, as well as inhibited Lyn/Syk in B cell receptor signaling pathway. Further experiments demonstrated that DCZ0014 did not significantly affect peripheral blood mononuclear cells. In vivo analysis showed that DCZ0014 not only significantly inhibited tumor growth but also extended the survival time of mice in the DCZ0014-treated group.

Conclusions: DCZ0014 showed potential for clinical application in the treatment of patients with DLBCL.

\section{Background}

Diffuse large $B$ cell lymphoma (DLBCL) is the most common subtype of non-Hodgkin's lymphoma (NHL). DLBCL is a heterogeneous, aggressive, malignant non-Hodgkin lymphoma, accounting for $30-40 \%$ of all $\mathrm{NHL}$ cases [1]. Based on its gene expression profile, the disease is mainly divided into three subtypes: germinal center B-cell-like DLBCL, activated B-cell-like DLBCL, and primary mediastinal B-cell lymphoma [2-4]. The International Prognostic Index score (IPI score) is widely used to predict the prognosis of DLBCL, which provides an important theoretical basis for guiding clinical medication and treatment. After the discovery of rituximab, a model first-line treatment of DLBCL using R-CHOP (rituximab plus cyclophosphamide, vincristine, doxorubicin, and prednisone) was developed. The 3-year event-free survival rate of patients with DLBCL is approximately $60 \%$. However, more than $30 \%$ of patients exhibit treatment failure, relapse, or refractory disease [5]. Therefore, novel drugs or targeted therapies are needed to improve the overall survival of patients with DLBCL.

The B cell receptor (BCR) signaling pathway, which is key to the development and maturation of normal $B$ cells, is a valuable target for treating B-cell malignancies [6-10]. Activated BCR-mediated signaling is 
involved in the pathogenesis of numerous NHLs, including mantle cell lymphoma (MCL), DLBCL, follicular lymphoma, gastric mucosa-associated lymphoid tissue lymphoma, and B-cell chronic lymphocytic leukemia [11-14]. Lyn kinase, a member of the SRC family of kinases, is involved in one of the earliest events after BCR stimulation [15]. Lyn is thought to be a key regulator of B cell homeostasis because of its ability to phosphorylate activators and inhibitors downstream of BCR activation. Lyn directly phosphorylates Syk, which is essential for further signal propagation. Additionally, Lyn activates phosphatases, which in turn inhibit signal transduction through BCR [7]. Activation of PI3K signaling is activated mainly by Lyn in the BCR pathway, which promotes cancer cell survival, proliferation, and invasion, such as in malignant lymphoma cells $[16,17]$. For many patients, BCR pathway inhibitors are rapidly becoming the first-choice treatment.

Herein, we report a novel analogue of berberine, DCZ0014 $\left(\mathrm{C}_{21} \mathrm{H}_{19} \mathrm{NO}_{5}\right)$, which has potent antitumor activity in human DLBCL cell lines in vitro and in vivo. We found that DCZ0014 significantly inhibited the proliferation of DLBCL cells and induced cell apoptosis. DLBCL cells treated with DCZ0014 clearly accumulated in G0/G1-phase of the cell cycle. We also showed that intraperitoneal injection of DCZ0014 effectively inhibited tumor growth in xenograft mouse models. These results provide a theoretical basis for the clinical application of DCZ0014 for treating patients with DLBCL.

\section{Materials And Methods}

\section{Cells and culture}

SUDHL-4 and DB cells were purchased from the American Type Culture Collection (ATCC) (Manassas, VA, USA). NU-DUL-1 and OCl-LY8 cells were obtained by Professor Xiaoyan Zhou (Department of Pathology, Fudan University of Shanghai Cancer Center, Shanghai, China). TMD8 and U2932 cells were kindly provided by Professor Dongsheng Xu (Shanghai Tenth People's Hospital, Tongji University of Medical, Shanghai, China). And GCB cell lines mainly includes SUDHL-4, DB, OCI-LY1 and OCI-LY8 and the NU-DUL1, U2932 and TMD8 are belong to ABC subtypes in the DLBCL cell lines. SUDHL-4, DB, NU-DUL-1, TMD8 and PBMCs were cultured in RPMI 1640 medium (Gibco, Carlsbad, CA, USA) containing 10\% FBS (FBS; Gibco, BRL, USA) and 1\% PS (PS; Gibco, Carlsbad, CA, USA). U2932 was cultured in Dulbecco's Modified Eagle's Medium/Low Glucose (Gibco, Carlsbad, CA, USA), supplemented with 10\% FBS and 1\% PS. OClLY1 and OCI-LY8 were cultured in Iscove's Modified Dulbecco's Medium (Gibco, Carlsbad, CA, USA) containing $10 \%$ FBS and $1 \%$ PS. All cells were incubated in a humidified atmosphere at $37^{\circ} \mathrm{C}, 5 \%$ carbondioxide.

\section{Reagents}

DCZ0014 stock solution was dissolved in dimethyl sulfoxide (DMSO; Sigma, St. Louis, MO, USA) and stored at $-20^{\circ} \mathrm{C}$. Antibodies for phospho-PI3K, cleaved caspase-3, cleaved Caspase-8, Caspase-9, poly ADP-ribose polymerase (PARP), Bax, Bad, B cell lymphoma-2 (Bcl-2), Bcl-xl, C-myc, Mcl-1 and $\beta$-actin (for western blot) were purchased from Cell Signaling Technology (Danvers, MA, USA). Lyn, phospho-Lyn, Syk, phospho-Syk, Akt, phospho-Akt, STAT3, phospho-STAT3, STAT1, phospho-STAT1, ATM, phospho-ATM, 
ATR, phospho-ATR, CHK2, phospho-checkpoint kinase2 (p-CHK2), CHK1, phospho-checkpoint kinase1 (pCHK1), cell division cycle 25A (cdc25A), CDK4, CDK6 and cyclinD1 antibodies were obtained from Abcam (Cambridge, MA, USA). The Cell Counting Kit-8 (CCK-8) was purchased from Dojindo (Kumamoto, Japan), the Annexin-V/ propidium iodide (PI) apoptosis detection kit from BD Pharmingen (Franklin Lakes, NJ, USA) and the JC-1 Kit from Beyotime Institute of Biotechnology (Haimen, China).

\section{Cell viability assay}

DLBCL cell lines (SUDHL-4, OCI-LY8, OCI-LY1, NU-DUL-1, TMD8, U2932 and DB) and PBMCs were seeded into 96 -well plates in $95 \mu \mathrm{L}$ complete media at a density of $2 \times 10^{5}$ cells $/ \mathrm{mL}$ and treated with different concentrations of DCZO014 (0, 0.5, 1, 2, 4 and $8 \mu \mathrm{M})$ for $48 \mathrm{~h}$. Cell proliferation was evaluated by $10 \mu \mathrm{L}$ of Cell Counting Kit-8 (CCK8, Dojindo, Kumamoto, Japan) adding into each well of the plate. Half maximal inhibitory concentration $\left(\mathrm{IC}_{50}\right)$ values were evaluated by using CalcuSyn software.

\section{Clonogenic assay}

OCI-LY8 and NU-DUL-1 cells were seeded in six-well plates at 1000 cells per well and incubated at $37^{\circ} \mathrm{C}$ incubator for 2 weeks. Cell colonies were stained with $0.1 \%$ crystal violet for 30 minutes. Colonies with at least 50 cells were counted.

\section{Analysis of cell cycle}

OCI-LY8 and NU-DUL-1 cells were cultured in 12-well plates at a density of $2 \times 10^{5}$ cells $/ \mathrm{mL}$ and treated with DCZ0014 ( 0 and $2 \mu \mathrm{M})$ and incubated for 12,24 or $48 \mathrm{~h}$. Then cells were collected and washed in PBS and fixed with ice cold 70\% ethanol overnight. After washed in PBS, cells were incubated with propidium iodide (PI) (BD Pharmingen, Franklin Lakes, NJ, USA) at room temperature for $15 \mathrm{~min}$ and analyzed by flow cytometry.

\section{TUNEL assay}

OCl-LY8 and NU-DUL-1 cells were exposed to DCZ0014 for $48 \mathrm{~h}$, collected, fixed in 4\% paraformaldehyde for 20 min, ruptured with $0.1 \%$ Triton X-100, stained with DAPI (Sigma-Aldrich, St. Louis, MO, USA) at room temperature for $15 \mathrm{~min}$ and then TUNEL (Roche, Basel, Switzerland)) at $37^{\circ} \mathrm{C}$ for $1 \mathrm{~h}$. The cells were imaged under a fluorescence microscope.

\section{EdU assay}

OCI-LY8 and NU-DUL-1 cells were exposed to DCZ0014 and treated with DCZ0014 ( 0 and $2 \mu \mathrm{M}$ ) for $48 \mathrm{~h}$ and collected. The incorporation of 5-ethynyl-2'-deoxyuridine (EdU) was measured using an EdU kit (RiboBio, Guangzhou, China) according to the manufacturer's instruction.

\section{Cell apoptosis analysis}

OCI-LY8 and NU-DUL-1 cells were cultured in 12-well plates at a density of $2 \times 10^{5}$ cells $/ \mathrm{mL}$ and treated with DCZ0014 (0, 1, 2 and $4 \mu \mathrm{M})$ and incubated for 12, 24, 36, 48 or $72 \mathrm{~h}$. Then according to the manufacturer's protocol. Then cells were collected and washed in PBS, and then stained with annexin V- 
FITC and PI (BD Pharmingen, Franklin Lakes, NJ, USA) with room temperature for 15 min incubating to detect apoptosis by a BD FASCCanto II flow cytometer (BD BioScience, San Jose, CA, USA).

\section{MMP analysis}

OCI-LY8 and NU-DUL-1 cells were cultured in 24-well plates at a density of $2 \times 10^{5}$ cells $/ \mathrm{mL}$ and treated with DCZ0014 (0 and $2 \mu \mathrm{M})$ and incubated for $48 \mathrm{~h}$, and incubated with $2 \mu \mathrm{M} \mathrm{JC}-1$ at $37^{\circ} \mathrm{C}$, in $5 \% \mathrm{CO}_{2}$ for 20 minutes. Then cells were collected and washed in PBS and analyzed with flow cytometry.

\section{Western blot analysis}

Cells treated with different concentrations of DCZ0014 and Total proteins were extracted with lysis buffer (100 mM Tris-HCL, PH 6.8, 4\% SDS, 20\% glycerol). Cytosolic proteins (30 $\mu \mathrm{g}$ per lane) were electrophoretically separated on a $6 \%$ or $15 \%$ sodium dodecyl sulfate-polyacrylamide gel (SDS-PAGE BioRad, CA, USA) and transferred electrophoretically onto polyvinylidene difluoride or nitrocellulose membranes, blocked in 5\% non-fat milk or $5 \%$ BSA for $1 \mathrm{~h}$, and incubated with the relevant primary antibodies overnight at $4{ }^{\circ} \mathrm{C}$. Membranes were washed with Phosphate-buffered saline (PBS) containing $0.1 \%$ Tween 20 (PBST) three times and incubated with the appropriate secondary antibodies (anti-rabbit or anti-mouse $\mathrm{lgG}$ ) for $1 \mathrm{~h}$ at room temperature. membranes were subsequently detected by the Odyssey two-color infrared laser imaging system (LI-COR, Lincoln, NE, USA).

\section{Cell transfection}

The small interfering RNAs (siRNAs) targeting human Lyn,the negative control siRNA were designed and constructed by RiboBio (Guangzhou, China) and the overexpression of Lyn plasmid were transfected into OCI-LY8 and NU-DUL-1 cells cultured in Opti-MEM (Gibco) by using Lipofectamine 3000 transfection reagent (Invitrogen, Carlsbad, CA, USA) up to a final concentration of $50 \mathrm{nM}$. The siRNA sequences (5'-3') were as follows: GCTGGAGCTTTCCTTATTA.

\section{Tumor xenograft model}

$2 \times 10^{6}$ OCl-LY8 cells in $100 \mu \mathrm{L}$ serum-free culture medium were inoculated subcutaneously into the BALB/C nude mice (Shanghai Laboratory Animal Center, Shanghai, China). When the tumors were measurable, mice were randomly divided into treatment groups receiving 15 mg/kg DCZ0014 or into a control group receiving vehicle (DMSO and saline). DCZ0014 was dissolved into 200 $\mu \mathrm{L}$ of vehicle. Mice were injected intraperitoneally with vehicle or DCZ0014 for 18 days. Tumor size and the body weight of mice were measured every other day. Tumor volume was determined as $1 / 2 \times(\text { width/2 })^{2} \times$ length. At the end of the experiment, mice were sacrificed. The tumors underwent hematoxylin-eosin (H\&E) staining, Ki67, cleaved-caspase 3, TUNEL, and immunohistochemical staining. The study protocol was approved by the Animal Care and Use Committee of The Tenth People's Hospital of Shanghai (ID: SYXK 2014-0026) and Tongji University (Shanghai, China).

\section{Statistical analysis}


The data were expressed as mean \pm standard deviation (SD). Student's t-test was performed as appropriate using SPSS v20.0 statistical analysis software (IBM, Armonk, NY, USA). $p<0.05$ was considered significant.

\section{Results}

\section{DCZ0014 inhibits the growth of diffuse large B cell lymphoma cells and their clones in vitro}

We investigated the effect of DCZ0014 on the proliferation of DLBCL cells (SUDHL-4, DB, OCI-LY8, NUDUL-1, TMD8, U2932, and OCI-LY1) using the CCK8 assay. The cell lines were treated with DCZ0014 at concentrations of $0.5,1,2,4$, and $8 \mu \mathrm{M}$ for 24,48 , and $72 \mathrm{~h}$. The results showed that DCZ0014 significantly inhibited the viability of DLBCL cells. Interestingly, DCZ0014 exhibited dose- and timedependent cytotoxicity in DLBCL cell lines (Fig. 1A-G). After treatment with DCZ0014 for $48 \mathrm{~h}$, the halfmaximal inhibitory concentration $\left(\mathrm{IC}_{50}\right)$ values of DCZ0014 in these cell lines were $2.0 \mu \mathrm{M}$ (NU-DUL-1), $4.1 \mu \mathrm{M}$ (U2932), $3.7 \mu \mathrm{M}$ (TMD8), 3.35 $\mu \mathrm{M}$ (SUDHL-4), 3.9 $\mu \mathrm{M}$ (DB), $0.8 \mu \mathrm{M}$ (OCI-LY8), and $0.04 \mu \mathrm{M}$ (OClLY1).

Based on the results described above, we selected two cell lines, OCI-LY8 cells in the germinal center Bcell-like DLBCL subtype and NU-DUL-1 in the activated B-cell-like DLBCL subtype, for further analysis. We then examined the effect of DCZ0014 on cloning of the two cell lines. Treatment with 0 and $2 \mu \mathrm{M}$ of DCZ0014 in NUDUL-1 and OCI-LY8 cells significantly inhibited the cloning of both cell types (Fig. 1I-J).

\section{DCZ0014 induces cell cycle arrest at G0/G1 phase in DLBCL cell lines in vitro}

To investigate whether inhibition of DLBCL cell proliferation is related to cell cycle arrest, flow cytometry and western blotting were performed to determine the effect of DCZ0014 on the DLBCL cell cycle. NUDUL-1 and OCI-LY8 cells were treated with different concentrations ( 0 and $2 \mu \mathrm{M})$ of DCZ0014 for 12, 24, and $48 \mathrm{~h}$. The results showed that DCZ0014 arrested NU-DUL-1 and OCI-LY8 cells in G0/G1 phase in a time-dependent manner (Fig. 2A-D). Additionally, DCZ0014 significantly reduced the expression levels of the cell cycle-associated proteins Cdc25A, CDK4/6, and cyclin D1 (Fig. 2E), further illustrating that G0/G1 phase arrest can be mediated by DCZ0014.

\section{DCZ0014 induces apoptosis of DLBCL cells and decreases MMP levels, but not in normal PBMCs}

To determine whether inhibition of the proliferation of DLBCL cells by DCZ0014 was caused by apoptosis induction, we examined the effect of DCZ0014 on apoptosis in DLBCL cells by using different concentrations $(0,1,2$ and $4 \mu \mathrm{M})$ of DCZ0014 to treat NU-DUL-1 and OCI-LY8 cells for $12,24,36$, 48, and $72 \mathrm{~h}$. The results of flow cytometry analysis showed that DCZ0014 significantly promoted the apoptosis 
of NU-DUL-1 and OCI-LY8 cells in a dose-and time-dependent manner (Fig. 3A-B). Additionally, TUNELpositive cells increased with increasing DCZ0014 doses in NU-DUL-1 and OCI-LY8 cells (Fig. 3A-B).

After the DLBCL cells were treated with different concentrations $(0,1,2$, and $4 \mu \mathrm{M})$ of DCZ0014 for $48 \mathrm{~h}$, western blotting was performed to detect the levels of apoptosis-related proteins, such as cleavedcaspase 3 and 8, caspase 9, PARP, Bcl-2, Bcl-xl, Bad, and Bax. The results showed that DCZ0014 significantly increased in the cleaved forms of caspase-3, caspase-8, caspase- 9 , and PARP and decreased the expression levels of $\mathrm{Bcl}-2$ and $\mathrm{Bcl}-\mathrm{xl}$ while up-regulating the expression levels of the proapoptotic proteins Bad and Bax (Fig. 3C). Thus, DCZ0014 induced apoptosis by activating both the extrinsic and intrinsic caspase pathways. We also analyzed the mitochondrial membrane potential (MMP), an indicator of cell apoptosis, in DLBCL cells by flow cytometry using a JC-1 kit. Notably, relative to the control group, DCZ0014 reduced the MMP in DLBCL cells (Fig. 3D).

To further confirm the toxic effects of DCZ0014, we investigated the effect of DCZ0014 on normal human primary blood mononuclear cells (PBMCs). We used different concentrations $(0,0.5,1,2,4$, and $8 \mu \mathrm{M})$ of DCZ0014 to treat normal PBMCs for $48 \mathrm{~h}$. The CCK-8 assay showed that DCZ0014 did not affect normal PBMCs (Fig. 3E), indicating that DCZ0014 was not toxic towards these cells and thus is a favorable drug for treating DLBCL.

\section{DCZ0014 inhibits DNA synthesis and aggravates DNA damage in DLBCL cells in vitro}

DCZ0014 was previously shown to inhibit the proliferation of DLBCL cells. We next examined the effect of DCZ0014 on DNA synthesis by treating DLBCL cells with different concentrations $(0$ and $2 \mu \mathrm{M})$ of DCZ0014 for $48 \mathrm{~h}$. The EdU incorporation assay showed that DCZ0014 significantly reduced the levels of EdU in NU-DUL-1 and OCI-LY8 cells (Fig. 4A-B). Additionally, NU-DUL-1 and OCI-LY8 cells were treated with different concentrations $(0,1,2$, and $4 \mu \mathrm{M})$ of DCZ0014 for $48 \mathrm{~h}$. The protein was extracted, and the expression levels of DNA damage-associated proteins was detected by western blotting. The results showed that DCZ0014 can activate ATM and ATR and phosphorylate the corresponding downstream molecules Chk2 and Chk1 (Fig. 4C).

\section{DCZ0014 inhibits Lyn/Syk in BCR signaling pathway}

We further assessed the expression patterns of molecules involved in the BCR signaling pathway by western blotting to determine the mechanism underlying DCZ0014-induced apoptosis. NU-DUL-1 and OClLY8 cells were treated with different concentrations $(0,1,2$, and $4 \mu \mathrm{M})$ of DCZ0014 for $48 \mathrm{~h}$. Proteins were extracted and subjected to western blotting to determine the effects of DCZ0014 on the BCR signaling pathway-associated protein Lyn/Syk. The results showed that DCZ0014 significantly inhibited the phosphorylation of Lyn/Syk and the phosphorylation of downstream proteins PI3K, AKT, and Stat1/3, as well as down-regulated the expression levels of C-myc and Mcl-1. Interestingly, the expression levels of total proteins Syk, PI3K, AKT, Stat1, and Stat3 did not change significantly (Fig. 5A). 
Then we further overexpress or knock out the Lyn gene and use Western blot to detect the effect of DCZ0014 on the Lyn/Syk signaling pathway. The results showed that when overexpressing Lyn gene, DCZ0014 could induce the apoptosis of NU-DUL-1 and OCI-LY8 cells more obviously and when the expression of Lyn was silenced, DCZ0014 reduced the induction of apoptosis in NU-DUL-1 and OCI-LY8 cells (Fig. 5B-E). And after overexpression or silencing of Lyn, DCZ0014 also has an effect on related proteins in the Lyn/Syk B cell receptor signaling pathway (Fig. 5D-E), indicating that DCZ0014 can exert anti-tumor effects by inhibiting the Lyn/Syk signaling pathway.

\section{DCZ0014 inhibits tumor growth in a DLBCL xenograft model in vivo}

We investigated the therapeutic efficacy of DCZ0014 by establishing a subcutaneous DLBCL xenograft model in nude mice. Specifically, five-week-old male BALB/c nude mice were injected with OCI-LY8 cells $\left(2.5 \times 10^{6}\right)$. We found that the tumor growth and tumor weight in mice treated with DCZ0014 at $15 \mathrm{mg} / \mathrm{kg}$ per day were significantly inhibited compared to in the vehicle-treated group (Fig. 6A-B). By simulating the tumor survival curve, the results showed that the survival time of mice in the DCZ0014-treated group was significantly longer than that in the vehicle-treated group $\left(P<0.001, P\right.$ value $\left.{ }^{* *}\right)$ (Fig. 6C). There was no significant difference in body weight between the two groups (Fig. 6D), indicating that DCZ0014 significantly inhibited tumor growth of the DLBCL xenograft in nude mice and the treatment was welltolerated.

Additionally, hematoxylin and eosin staining showed that the necrosis of tumor tissue was significantly increased in the DCZ0014-treated group compared to in the vehicle-treated group (Fig. 6E). We also found that the liver and kidney tissues of nude mice in the vehicle-treated group and DCZ0014-treated group exhibited no significant histological changes (Fig. 6F), further indicating that DCZ0014 does not cause significant toxicity. Analysis of the expression levels of cleaved-caspase 3 and TUNEL in the DCZ0014treated group was significantly increased compared to that in the vehicle-treated group (Fig. 6G), indicating that DCZ0014 significantly induced tumor cell apoptosis. We also found that the expression levels of Ki-67 in the DCZ0014 -treated group were significantly reduced (Fig. 6G), indicating that DCZ0014 inhibits the proliferation of subcutaneous DLBCL xenografts.

\section{Discussion}

DLBCL accounts for $30 \%$ of lymphoma and is the most common type [1]. Although standard chemotherapy with the R-CHOP regimen for patients with DLBCL can prolong event-free and overall survival, this treatment is ineffective or relapse or resistance to treatment is observed in more than $30 \%$ of patients [5]. Therefore, novel drugs or targets therapies that can improve the overall survival of patients with DLBCL should be developed.

DCZ0014, a novel analogue of berberine, was obtained by drug design and synthesis and was shown to have pro-apoptotic effects in many hematological tumor cells. In this study, we found that DCZ0014 significantly inhibited proliferation and induced apoptosis of DLBCL cells. Additionally, cells accumulated 
in the G0/G1 phases. Our experiments also showed that DCZ0014 did not significantly affect PBMCs. In vivo experiments in mice showed that DCZ0014 significantly inhibited tumor growth and that the treatment was well-tolerated.

In our in vitro study, we found that DCZ0014 markedly induced the growth inhibition of DLBCL cell lines in a dose- and time-dependent manner in the CCK-8 assay. These results were consistent with those of flow cytometric analysis. Caspase is a member of the cysteine protease family and can directly participate in and perform cell apoptosis. Caspase- 8 and caspase- 9 are the two key proteins activated in the extrinsic and intrinsic apoptotic pathways, respectively. Caspase 3 can cleave PARP [18]. Additionally, Bcl-2, Bcl-xl, Bad, and Bax play important roles in apoptosis [19-21]. Our results showed that DCZ0014 exerted its anti-tumor effects by inducing cell apoptosis by activating caspases, including by up-regulating the expression of cleaved-caspase 3, cleaved-caspase 8, cleaved-caspase 9 , and PARP, as well as by downregulating the protein levels of $\mathrm{Bcl}-2$ and $\mathrm{Bcl}-\mathrm{xl}$ along with concomitantly increasing the levels of $\mathrm{Bax}$ and Bad in DCZ0014-treated DLBCL cells. We further examined MMP, an indicator of mitochondrial membrane permeability, which is altered during early intrinsic apoptosis [22]. The mitochondrial pathway (also known as the endogenous pathway) is the control center for inducing apoptosis, and the stability of the transmembrane potential is necessary for its function [23]. Interestingly, JC-1 assessment demonstrated that DCZ0014 regulated the loss of MMP. These data suggest that DCZ0014 induces DLBCL cell apoptosis via both extrinsic and intrinsic apoptotic pathways through a process regulated by MMP levels and the caspase-dependent pathway.

Inhibition of cell proliferation is regulated via not only cell apoptosis but also cell cycle arrest [24]. The mechanism of currently used anti-tumor drugs also involves the cell cycle to inhibit tumor cell proliferation by arresting this cycle, thereby inhibiting the occurrence and development of tumors $[25,26]$. DCZ0014 was also found to induce the cell cycle in DLBCL cell lines. Further analysis showed that DCZ0014 arrested DLBCL cells in $\mathrm{G}_{0} / \mathrm{G}_{1}$ phase, as well as induced DNA damage and inhibited DNA synthesis. The important complex cyclin $D 1 / C D K 4 / C D K 6$ in $G_{0} / G_{1}$ phase plays a key role in regulating the progression from $G_{0} / G_{1}$ phase to $G_{2} / M$ phase [27]. Western blot analyses showed that DCZ0014-induced $\mathrm{G}_{0} / \mathrm{G}_{1}$ phase arrest significantly downregulated the protein expression levels of cyclin D1, CDK4, and CDK6. Our western blot results indicated that DCZ0014 treatment downregulated the expression of cdc25A and upregulated the levels of p-CHK1 and p-CHK2. CHK2 is an important protein kinase at the DNA damage checkpoint that can directly regulate cdc25A, which is associated with cell cycle control and the induction of DNA damage [28-30] During tumor development, an increase in the DNA damage response can significantly inhibit the development of tumors. ATM/ATR can reflect the damage to DNA and transmit signals to its downstream molecules Chk2/Chk1. This eventually results in cell cycle arrest or apoptosis initiation $[25,31]$. Our results suggest that DCZ0014-induced cell cycle arrest is mediated by the cdc25A-degradation pathway and DNA damage.

We further investigated the molecular mechanisms underlying DCZ0014 lethality in DLBCL. Activated BCR-mediated signaling is involved in the pathogenesis of a number of NHLs, including diffuse large Bcell lymphoma (DLBCL) [11-14]. BCR aggregation rapidly activates the Src family kinases Lyn, Blk, and 
Fyn as well as the Syk and Btk tyrosine kinases [32]. Activation of PI3K signaling is activated mainly by Lyn in the BCR pathway. Activated PI3K/AKT signaling is an important pathway in DLBCL. The Akt pathway acts upstream of Stat3 phosphorylation, which inhibits cell proliferation and differentiation [33, 34]. Stat3 is a crucial protein in DLBCL whose phosphorylation can regulate multiple genes downstream that are associated with apoptosis and the cell cycle, such as Bcl-2, Bcl-xL, Mcl-1, and c-Myc [35-37]. Accordingly, we explored whether DCZ0014 affects the BCR signaling pathway. As expected, our data showed that DCZ0014 inhibited activation of Lyn/Syk by reducing their phosphorylation and by downregulating the phosphorylation of $\mathrm{PI} 3 \mathrm{~K}, \mathrm{AKT}$, and Stat1/3. We then overexpressed or knocked out the Lyn gene. The results showed that when the Lyn gene was overexpressed, DCZ0014 induced apoptosis of cells more obviously; when Lyn was silenced, DCZ0014 reduced cell apoptosis. These results demonstrate that DCZ0014 induces apoptosis in DLBCL cells by decreasing PI3K/AKT activation through its effects on the Lyn/Syk B-cell receptor signaling pathways (Fig. 7).

To further confirm the anti-DLBCL activity of DCZ0014, we next examined its effects in vivo by establishing a DLBCL xenograft mouse model. Our data showed that DCZ0014 not only significantly inhibited tumor growth, but also caused no obvious toxicity in mice. Immunohistochemical staining of harvested tumors confirmed the DCZ0014-induced anti-proliferation and pro-apoptotic effects in DLBCL cells. Consistent with our in vitro results, these in vivo results demonstrate that DCZ0014 is a potent antitumor agent for treating DLBCL.

\section{Conclusion}

In conclusion, we showed that DCZ0014 can inhibit the proliferation of DLBCL cell lines and induce the apoptosis of DLBCL cells as well as cause cell cycle arrest at the $G_{0} / G_{1}$ stage in association with reduced $\mathrm{PISK} / \mathrm{AKT}$ activation by regulating the Lyn/Syk B-cell receptor signaling pathways. Consistent with our in vitro results, DCZ0014 inhibited tumor growth in vivo. This study provides a theoretical basis for the clinical application of DCZ0014 for treating patients with DLBCL. However, the detailed mechanisms and clinical effects in DLBCL require further investigation.

\section{Abbreviations}

DLBCL: diffuse large B cell lymphoma; NHL: non-Hodgkin's lymphoma; IPI score: International Prognostic Index score; R-CHOP: rituximab, cyclophosphamide, vincristine, doxorubicin and prednisone; BCR: B cell receptor; FBS: fetal bovine serum; PBMC: peripheral blood mononuclear cell; DMSO: dimethyl sulfoxide; MCL-1: mantle cell lymphoma 1; STAT1/3: signal transducers and activators of transcription 1/3; PI3K: phosphatidylinositol 3-kinase; CDK4/6: Cyclin-dependent kinase 4/6; PARP: poly ADP-ribose polymerase; CHK1: checkpoint kinase1; CHK2: checkpoint kinase2; Cdc25: cell division cycle 25; IL-6: Interleukin-6; IGF1: Insulin-like Growth Factors-1; BSA: albumin from bovine serum; CCK-8: cell counting kit-8; IC50: halfmaximal inhibitory concentration; PI: propidium iodide; MMP: mitochondrial membrane potential; EDU: 5ethynyl-2'-deoxyuridine; H\&E: hematoxylin and eosin; TUNEL: TdT-mediated dUTP Nick-End Labeling. 


\section{Declarations}

Acknowledgements

Thanks for the technical assistance of Zhiqiang Li.

\section{Authors' Contributions}

JMS initiated the study and designed the experiments. SKC performed the majority of the experiments and wrote the manuscript. BL, YCW and QLF performed the experiments and analyzed the data. ZJX, YT, RW, YML, YZ, YSX, WML and XSW collected primary samples for the study. WLZ and JMS supervised the experiments.

\section{Funding}

This work was supported by the National Natural Science Foundation of China (No. 81670194, 81870158 and 81900211) and National Science \& Technology Major Project "Key New Drug Creation and Manufacturing Program", China (Number:2018ZX09711002). Natural Science Foundation of Shanghai, China (19ZR1467800).

\section{Availability of data and materials}

The data are available to academic researchers upon request.

\section{Ethics approval and consent to participate}

Written informed consent was obtained from all subjects. All animal experiments were conducted in agreement with the Guide for the Care and Use of Laboratory Animals and were approved by the Animal Care and Use Committee of The Tenth People's Hospital of Shanghai (ID: SYXK 2014-0026) and Tongji University (Shanghai, China).

\section{Consent for publication}

Written informed consent for publication was obtained from all participants.

\section{Conflict of Interest}

The authors declare no conflict of interest.

\section{References}

1. The Non-Hodgkin's Lymphoma Classification Project. A clinical evaluation of the International Lymphoma Study Group classification of non- Hodgkin's lymphoma. Blood. 1997;89(11):3909-3916.

2. Alizadeh AA, Eisen MB, Davis RE, Ma C, Lossos IS, Rosenwald A, et al. Distinct types of diffuse large B-cell lymphoma identified by gene expression profiling. Nature. 2000;403(6769):503-11. 
3. Rosenwald A, Wright G, Chan WC, Connors JM, Campo E, Fisher RI, et al. The use of molecular profiling to predict survival after chemotherapy for diffuse large-B-cell lymphoma. $\mathrm{N}$ Engl $\mathrm{J}$ Med. 2002;346(25):1937-47.

4. Savage KJ, Monti S, Kutok JL, Cattoretti G, Neuberg D, de Leval L, et al. The molecular signature of mediastinal large B-cell lymphoma differs from that of other diffuse large B-cell lymphomas and shares features with classical Hodgkin lymphoma. Blood 2003;102(12):3871-9.

5. Pasqualucci L, Dalla-Favera R. SnapShot: diffuse large B cell lymphoma. Cancer Cell 2014;25(1):132.

6. Young RM, Staudt LM. Targeting pathological B cell receptor signalling in lymphoid malignancies. Nat Rev Drug Discovery. 2013;12(3):229-43.

7. Stevenson FK, Krysov S, Davies AJ, Steele AJ, Packham G. B-cell receptor signaling in chronic lymphocytic leukemia. Blood. 2011;118(16):4313-20.

8. Wiestner A. Targeting B-Cell receptor signaling for anticancer therapy: the Bruton's tyrosine kinase inhibitor ibrutinib induces impressive responses in B-cell malignancies. J.Clin.Oncol. 2013;31(1):128-30.

9. Woyach JA, Johnson AJ, Byrd JC. The B-cell receptor signaling pathway as a therapeutic target in CLL. Blood. 2012;120(6):1175-84.

10. Davids MS, Brown JR. Targeting the B cell receptor pathway in chronic lymphocytic leukemia. Leuk Lymphoma. 2012;53(12):2362-70.

11. Davis RE, Ngo VN, Lenz G, Tolar P, Young RM, Romesser PB, et al. Staudt LM. Chronic active B-cellreceptor signalling in diffuse large B-cell lymphoma. Nature. 2010;463(7277):88-92.

12. Deglesne PA, Chevallier N, Letestu R, Baran-Marszak F, Beitar T, Salanoubat C, et al. Survival response to B-cell receptor ligation is restricted to progressive chronic lymphocytic leukemia cells irrespective of Zap70 expression. Cancer Res. 2006;66(14):7158-7166.

13. Kuppers R. Mechanisms of B-cell lymphoma pathogenesis. Nat Rev Cancer. 2005;5(4):251-262.

14. Rodriguez A, Villuendas R, Yanez L, Gomez ME, Diaz R, Pollan M, et al. Molecular heterogeneity in chronic lymphocytic leukemia is dependent on BCR signaling: clinical correlation. Leukemia. 2007;21(9):1984-1991.

15. Yamanashi Y, Kakiuchi T, Mizuguchi J, Yamamoto T, Toyoshima K. Association of B cell antigen receptor with protein tyrosine kinase Lyn. Science. 1991;251(4990):192-194.

16. Lannutti BJ, Meadows SA, Herman SE, Kashishian A, Steiner B, Johnson AJ, et al. CAL-101, a p110delta selective phosphatidylinositol-3-kinase inhibitor for the treatment of B-cell malignancies, inhibits PI3K signaling and cellular viability. Blood. 2011;117(2):591-4.

17. Rudelius M, Pittaluga S, Pham TH, Fend F, Jaffe ES, Raffeld, Me, et al. Constitutive activation of Akt contributes to the pathogenesis and survival of mantle cell lymphoma. Blood. 2006;108(5):1668-76.

18. Taylor RC, Cullen SP, Martin SJ. Apoptosis: controlled demolition at the cellular level. Nature Reviews Molecular Cell Biology. 2008;9(3):231-241. 
19. Kiraz Y, Adan A, Yandim MK, Baran Y. Major apoptotic mechanisms and genes involved in apoptosis. Tumour Biol. 2016;37(7):8471-8486.

20. Amin HM, Ergin M, Denning MF, Quevedo ME, Alkan S. Characterization of apoptosis induced by protein kinase $C$ inhibitors and its modulation by the caspase pathway in acute promyelocytic leukaemia. Br J Haematol. 2000;110(3):552-562.

21. Wiebe JP, Beausoleil M, Zhang G, Cialacu V. Opposing actions of the progesterone metabolites, 5 alpha-dihydroprogesterone (5 alpha $\mathrm{P}$ ) and 3 alpha-dihydroprogesterone ( 3 alpha HP) on mitosis,apoptosis, and expression of Bcl-2, Bax and p21 in human breast cell lines. J Steroid Biochem Mol Biol. 2010;118(1-2):125-132.

22. Xie B, Xu Z, Hu L, Chen G, Wei R, Yang G, et al. Pterostilbene Inhibits Human Multiple Myeloma Cells via ERK1/2 and JNK Pathway In Vitro and In Vivo. Int J Mol Sci. 2016;17(11):1927.

23. Ly JD, Grubb DR, Lawen A. the mitochondrial membrane potential $(\delta \psi m)$ in apoptosis; an update. Apoptosis. 2003;8(2):115-128.

24. H Niknejad, G Yazdanpanah, A Ahmadiani. Induction of apoptosis, stimulation of cell-cycle arrest and inhibition of angiogenesis make human amnion-derived cells promising sources for cell therapy of cancer. Cell Tissue Res. 2016;363(3):599-608.

25. Kastan MB, Bartek J. Cell-cycle checkpoints and cancer. Nature. 2004;432(7015): 316-323.

26. Visconti R, Della Monica R, Grieco D. Cell cycle checkpoint in cancer: a therapeutically targetable double-edged sword. J Exp Clin Cancer Res. 2016;35(1):153.

27. Bhattacharya K, Bag AK, Tripathi R, Samanta SK, Pal BC, Shaha C, et al. Mahanine, a novel mitochondrial complex-III inhibitor induces G0/G1 arrest through redox alteration-mediated DNA damage response and regresses glioblastoma multiforme. Am J Cancer Res. 2014;4(6):629-47.

28. Dai B, Zhao XF, Mazan-Mamczarz K, Hagner P, Corl S, Bahassi el M, et al. Functional and molecular interactions between ERK and CHK2 in diffuse large B-cell lymphoma. Nat Commun. 2011;2:402.

29. Zannini L, Delia D, Buscemi G. CHK2 kinase in the DNA damage response and beyond. J Mol Cell Biol. 2014;6(6):442-57.

30. Yuan Z, Guo W, Yang J, Li L, Wang M, Lei Y, et al. PNAS-4, an Early DNA Damage Response Gene, Induces S Phase Arrest and Apoptosis by Activating Checkpoint Kinases in Lung Cancer Cells. J Biol Chem. 2015;290(24):14927-44.

31. Walters DK, Wu X, Tschumper RC, Arendt BK, Huddleston PM, Henderson KJ, et al. Evidence for ongoing DNA damage in multiple myeloma cells as revealed by constitutive phosphorylation of H2AX. Leukemia. 2011;25(8):1344-1353.

32. Niemann CU, Wiestner A. B-cell receptor signaling as a driver of lymphoma development and evolution. Semin Cancer Biol. 2013;23(6):410-21.

33. SQ He, M Gao, YF Fu, YN Zhang. Glycyrrhizic acid inhibits leukemia cell growth and migration via blocking AKT/mTOR/STAT3 signaling. Int J Clin Exp Pathol. 2015;8(5):5175-81. 
34. Chen X, Hao A, Li X, Du Z, Li H, Wang H, et al. Melatonin inhibits tumorigenicity of glioblastoma stemlike cells via the AKT-EZH2-STAT3 signaling axis. J Pineal Res. 2016;61(2):208-217.

35. Ashizawa T, Miyata $\mathrm{H}$, Ishii $\mathrm{H}$, Oshita $\mathrm{C}$, Matsuno $\mathrm{K}$, Masuda $\mathrm{Y}$, et al. Antitumor activity of a novel small molecule STAT3 inhibitor against a human lymphoma cell line with high STAT3 activation. Int J Oncol. 2011;38(5):1245-1252.

36. P Sepulveda, A Encabo, F Carbonell-Uberos, MD Miñana. BCL-2 expression is mainly regulated by JAK/STAT3 pathway in human CD34+ hematopoietic cells. Cell Death and Differentiation. 2006;14(2):378-380.

37. Verma NK, Davies AM, Long A, Kelleher D, Volkov Y. STAT3 knockdown by siRNA induces apoptosis in human cutaneous T-cell lymphoma line Hut78 via downregulation of Bcl-xL. Cell Mol Biol Lett. 2010;15(2):342-55.

\section{Figures}

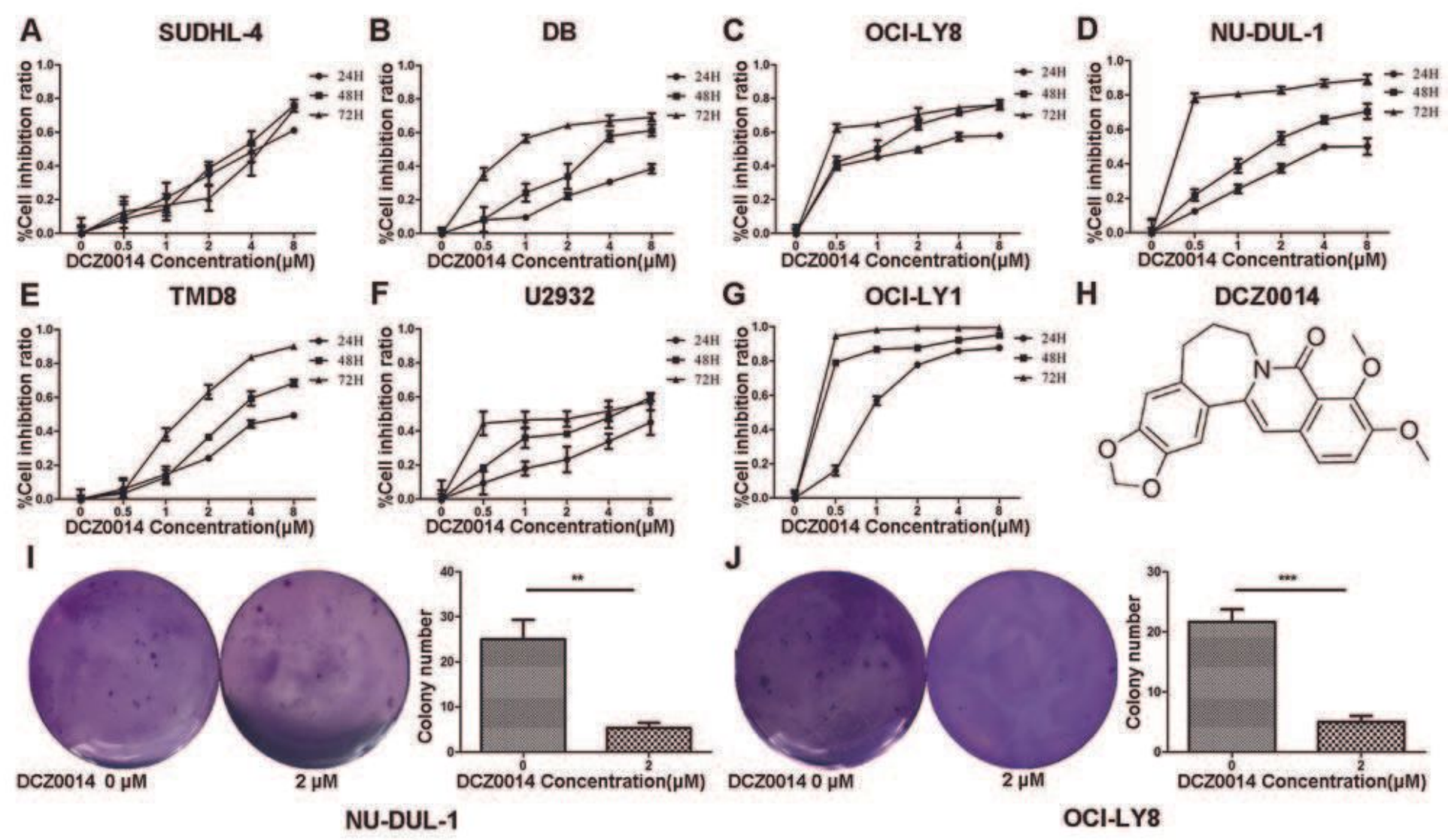

\section{Figure 1}

DCZ0014 inhibits the growth of diffuse large B-cell lymphoma cells and their clones in vitro. (A) SUDHL-4 cells were treated with DCZ0014 $(0.5,1,2,4$, and $8 \mu \mathrm{M})$ for 24,48 , and $72 \mathrm{~h}$. (B) DB cells were treated with DCZ0014 $(0.5,1,2,4$, and $8 \mu \mathrm{M})$ for 24,48 , and $72 \mathrm{~h}$. (C) OCI-LY8 cells were treated with DCZO014 $(0.5,1$, $2,4$, and $8 \mu \mathrm{M})$ for 24,48 , and $72 \mathrm{~h}$. (D) NU-DUL-1 cells were treated with DCZ0014 $(0.5,1,2,4$, and $8 \mu \mathrm{M})$ 
for 24,48 , and $72 \mathrm{~h}$. (E) TMD8 cells were treated with DCZ0014 $(0.5,1,2,4$, and $8 \mu \mathrm{M})$ for 24,48 , and $72 \mathrm{~h}$. (F) U2932 cells were treated with DCZ0014 $(0.5,1,2,4$, and $8 \mu \mathrm{M})$ for 24,48 , and $72 \mathrm{~h}$. (G) OCI-LY1 cells were treated with DCZ0014 $(0.5,1,2,4$, and $8 \mu \mathrm{M})$ for 24,48 , and $72 \mathrm{~h}$. Cell viability was measured using a cell counting kit-8 (CCK-8). (H) Chemical structure of DCZ0014. Colony formation assays demonstrated the colony-forming ability of the cells and cells treated with DCZ0014 $(0,2 \mu \mathrm{M})$. NU-DUL-1 (I) and OCI-LY8 (J) cells are shown. ${ }^{* * P}<0.01,{ }^{* *} \mathrm{P}<0.001$.

A

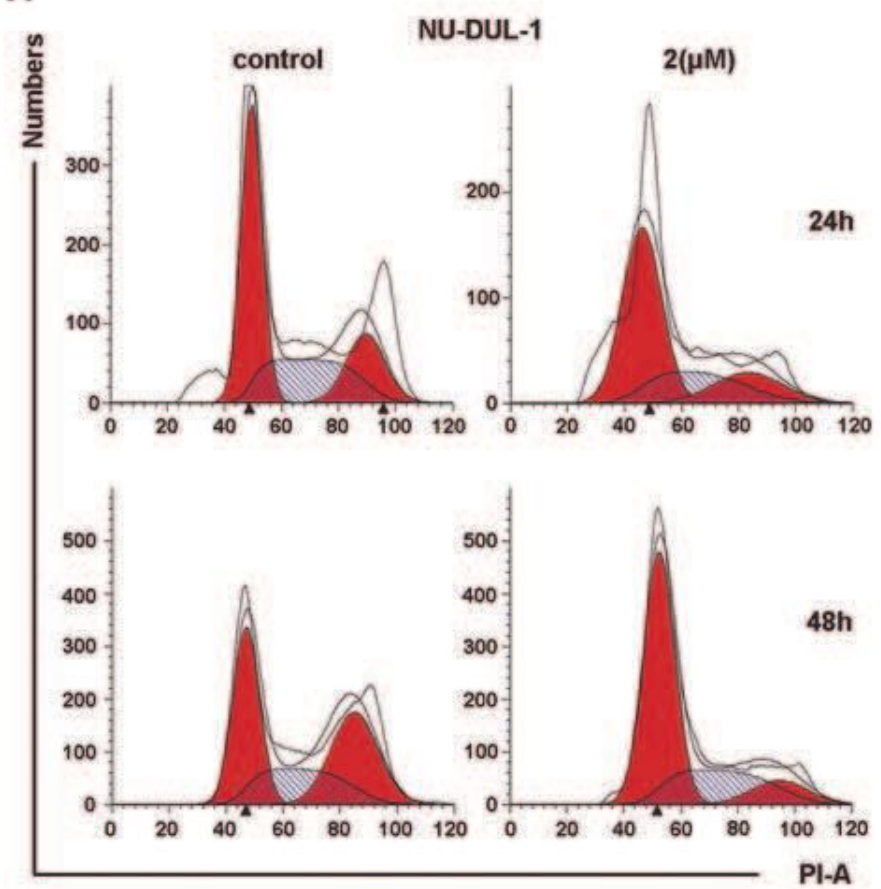

C

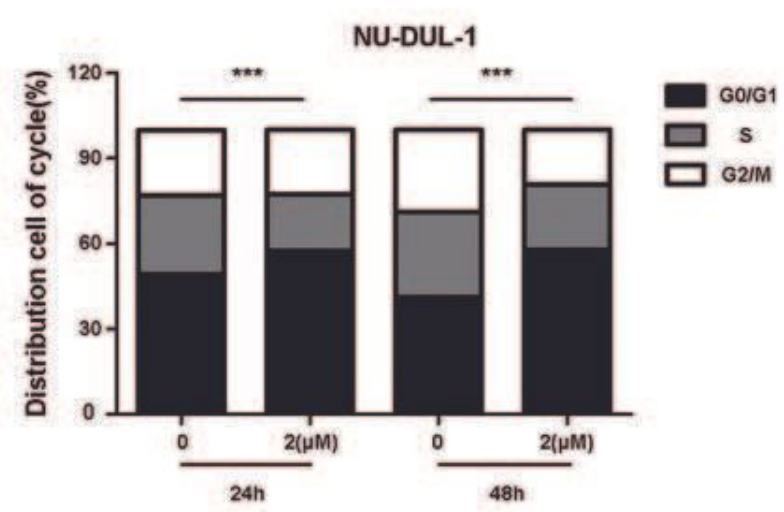

E

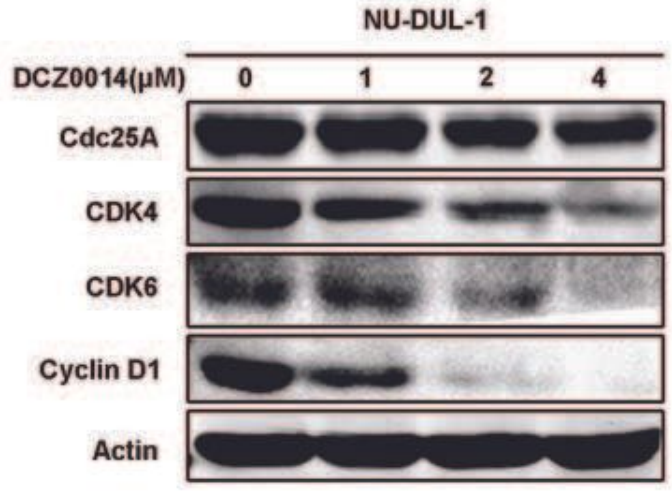

B

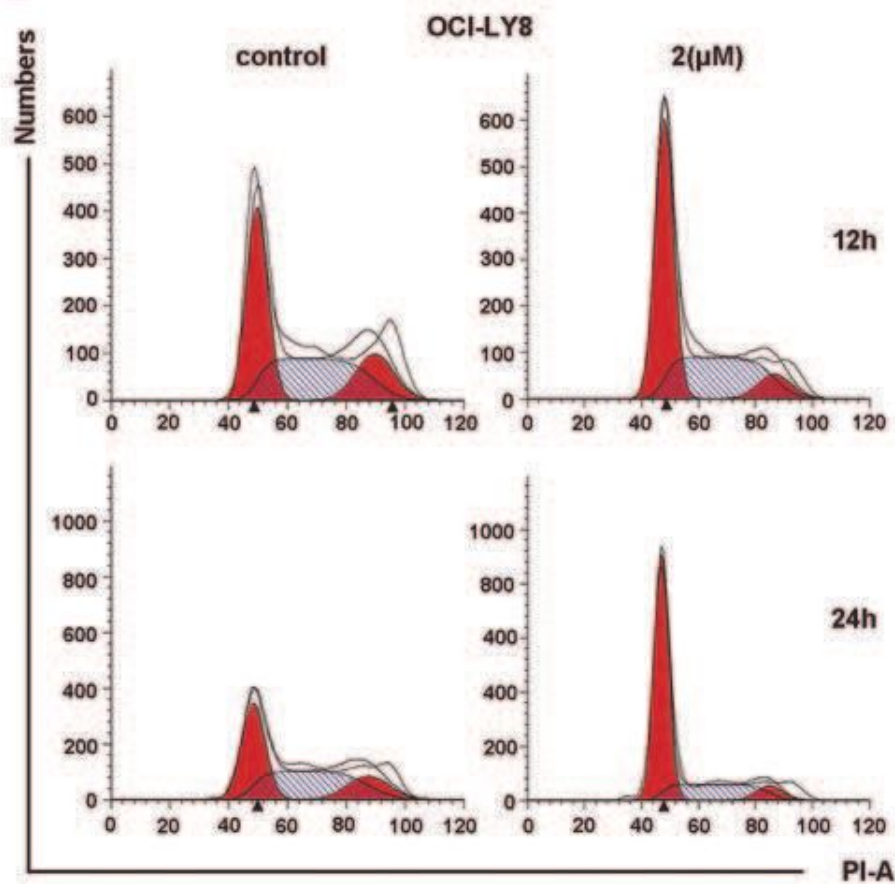

D

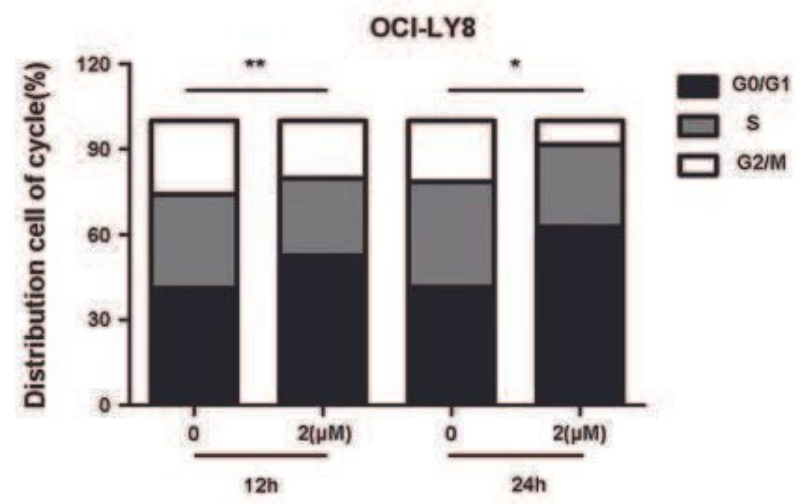

OCI-LY8

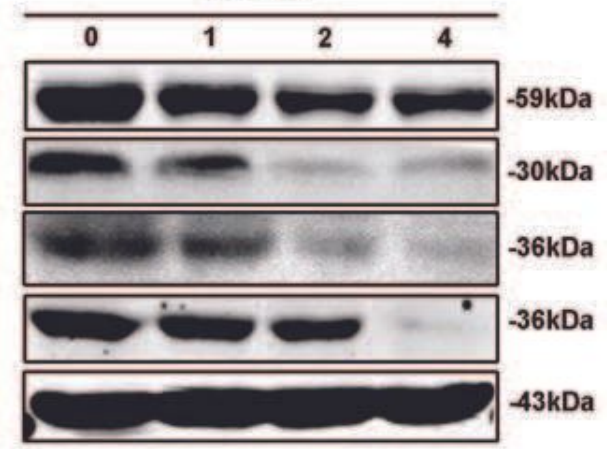

Figure 2 
DCZ0014 induces cell cycle arrest at the G0/G1 phase in DLBCL cell lines in vitro. (A) NU-DUL-1 cells were treated with DCZ0014 $(0$ and $2 \mu \mathrm{M})$ for 24 and $48 \mathrm{~h}$ while (B) OCI-LY8 cells were treated with DCZ0014 (0 and $2 \mu \mathrm{M}$ ) for 12 and $24 \mathrm{~h}$, and the cell cycle was analyzed by propidium iodide staining using flow cytometry. The percentage of the NU-DUL-1 cells (C) and OCI-LY8 cells (D) in G0/G1 phase. *P囚0.05, **P区 0.01 , $* \star * P \llbracket 0.001$. (E) Cells were treated with $\operatorname{DCZ0014}(0,1,2$, and $4 \mu M)$ for $24 \mathrm{~h}$, and western blot analysis was performed to detect the protein levels of cdc25A, CDK4, CDK6, and cyclin D1.

A

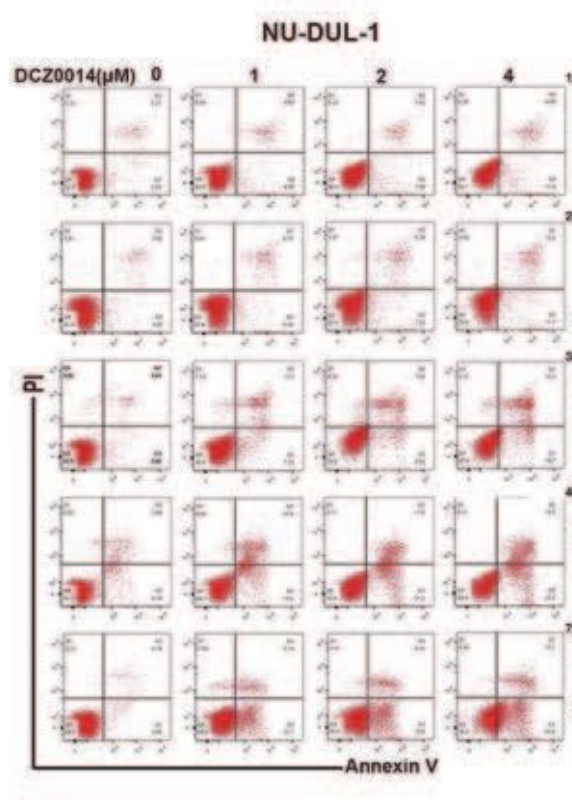

C

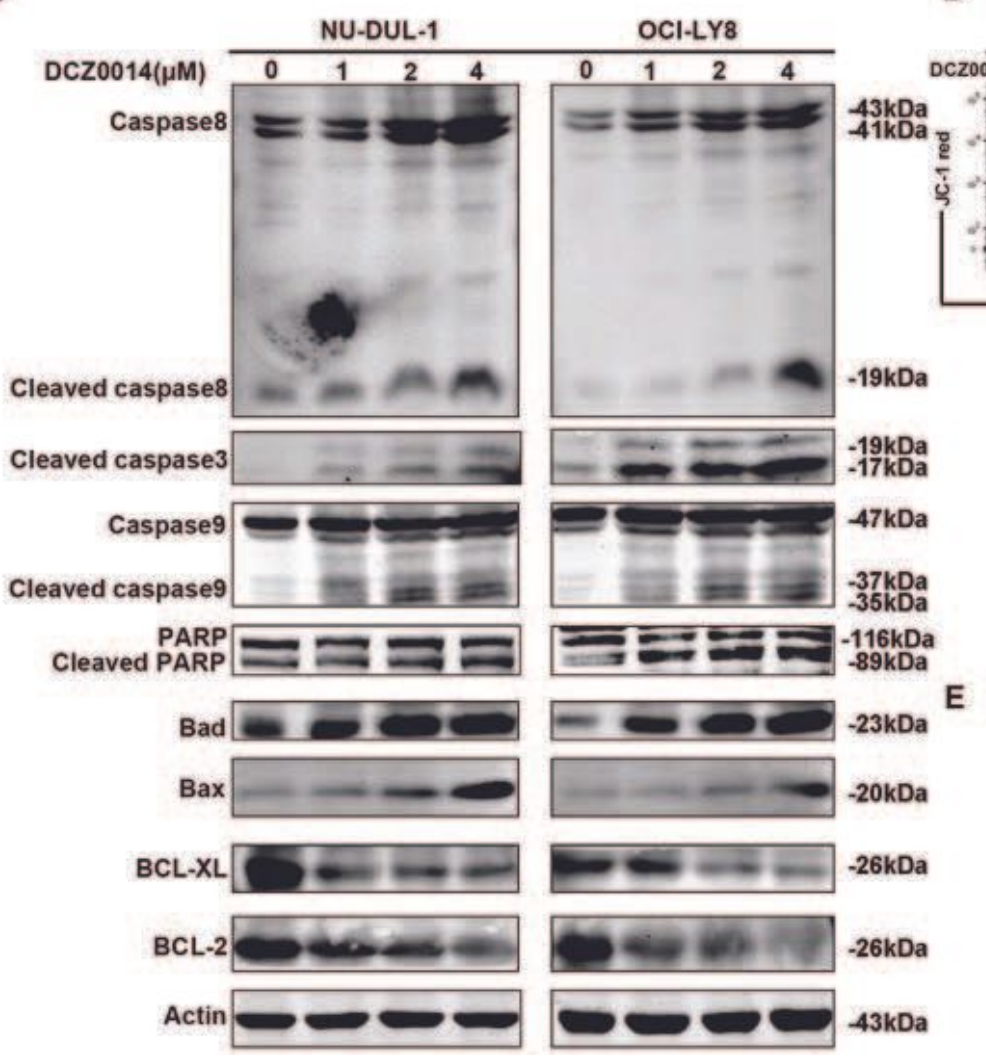

B

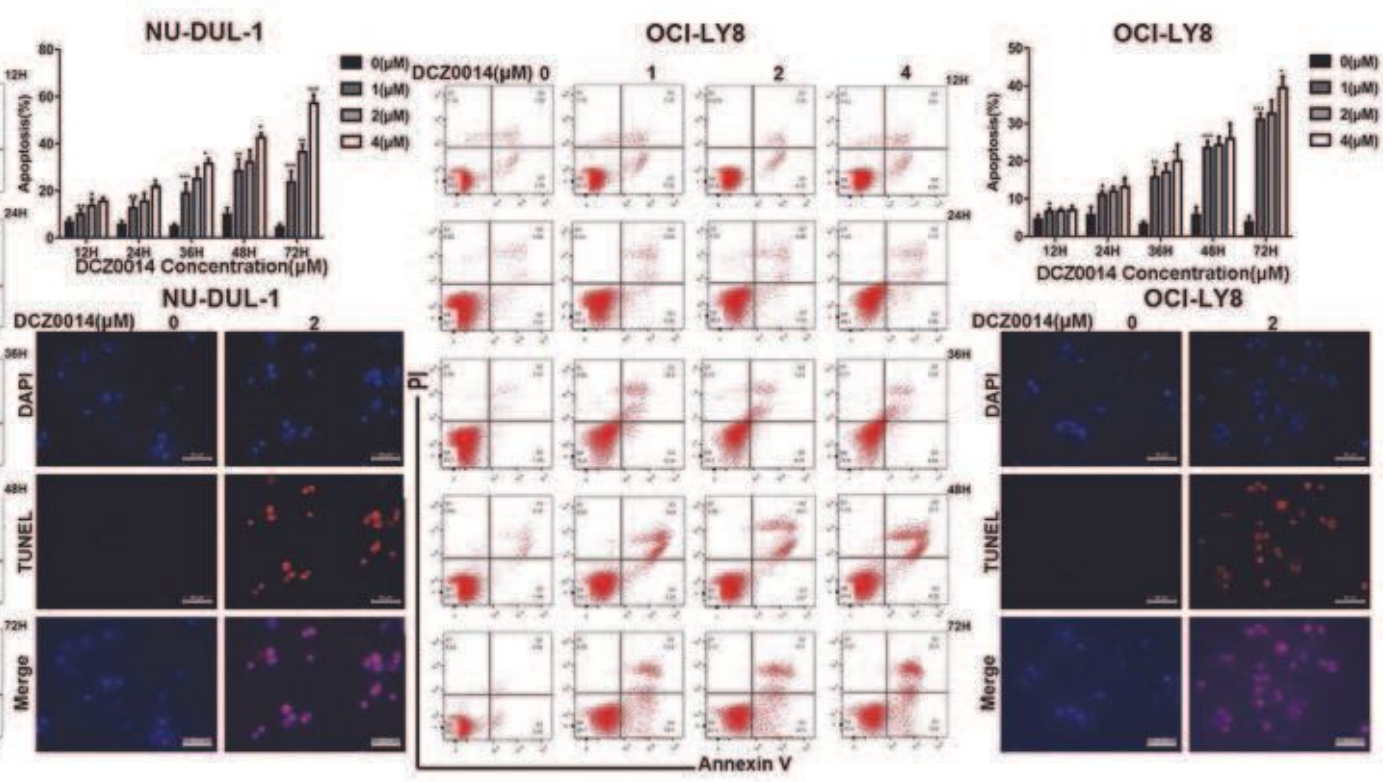

D
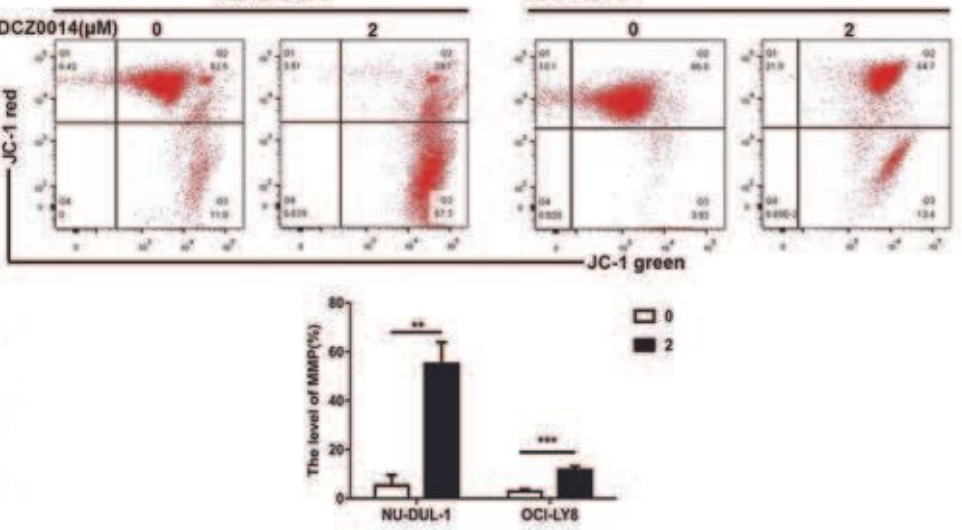

무

2

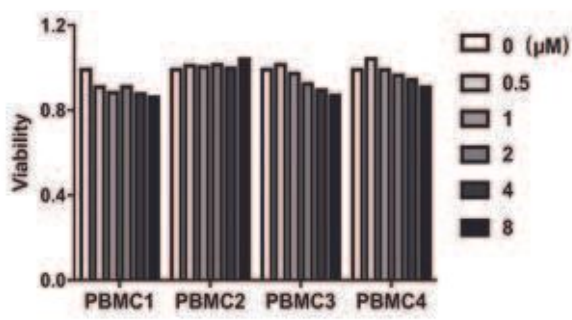

Figure 3 
DCZ0014 induces the apoptosis of DLBCL cells, but it has no toxicity towards normal PBMCs. NU-DUL-1 cells (A) and OCl-LY8 cells (B) were treated with DCZ0014 $(0,1,2$, and $4 \mu \mathrm{M})$ for $12,24,36,48$, or $72 \mathrm{~h}$, and then apoptosis was detected by TUNEL assay or Annexin-V/PI staining followed by flow cytometry; the percentage of Annexin-V-positive cells is shown. Red indicates TUNEL-positive cells (400x magnification). $* P \otimes 0.05, * \star P \otimes 0.01, * * * P \otimes 0.001$. (C) Cells were treated with DCZ0014 $(0,1,2$, and $4 \mu \mathrm{M})$ for $48 \mathrm{~h}$, and western blot analysis was performed to detect the protein levels of cleaved-caspase 3,8 , caspase 9 , PARP, $\mathrm{Bcl}-2$, Bcl-xl, Bad, and Bax. (D) Cells treated with DCZ0014 $(0$ and $2 \mu \mathrm{M})$ after $48 \mathrm{~h}$ and were evaluated to determine the mitochondrial membrane potential (MMP) by JC-1 staining by flow cytometry. JC-1 showed

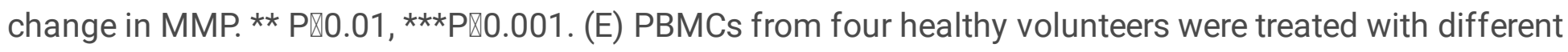
concentrations of DCZ0014 $(0.5,1,2,4$, and $8 \mu \mathrm{M})$ for $48 \mathrm{~h}$. Cell viability was measured using a cell counting kit-8 (CCK-8). 
A

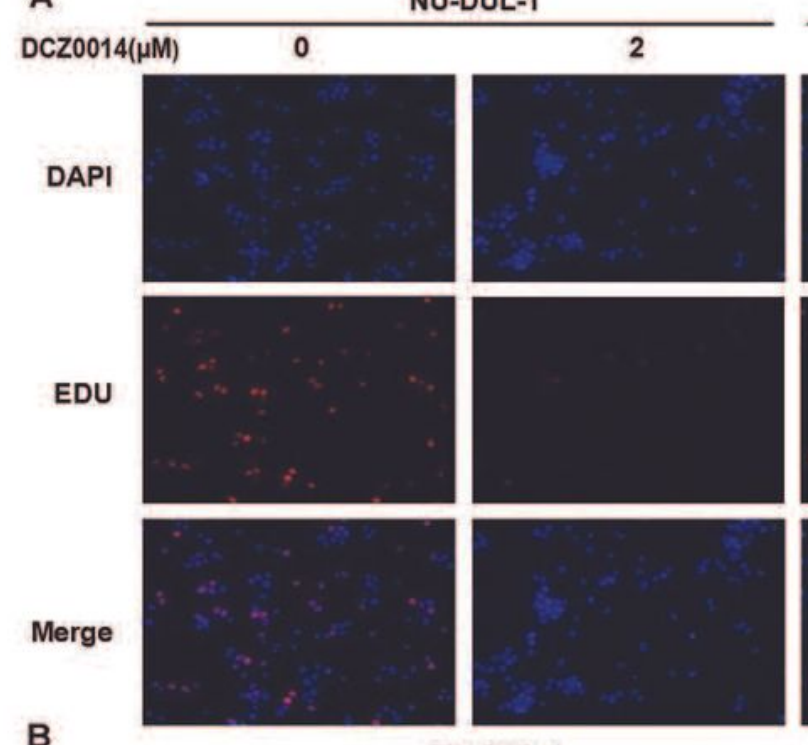

B

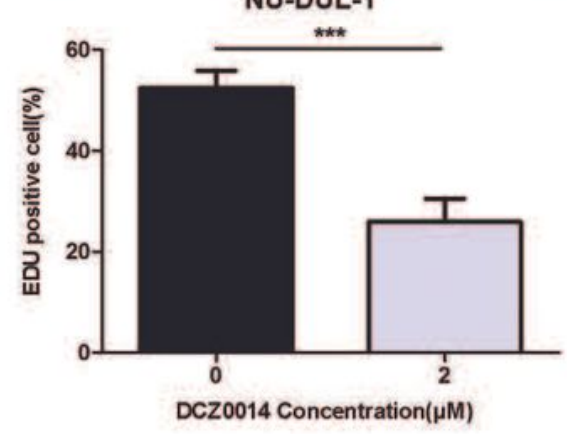

C

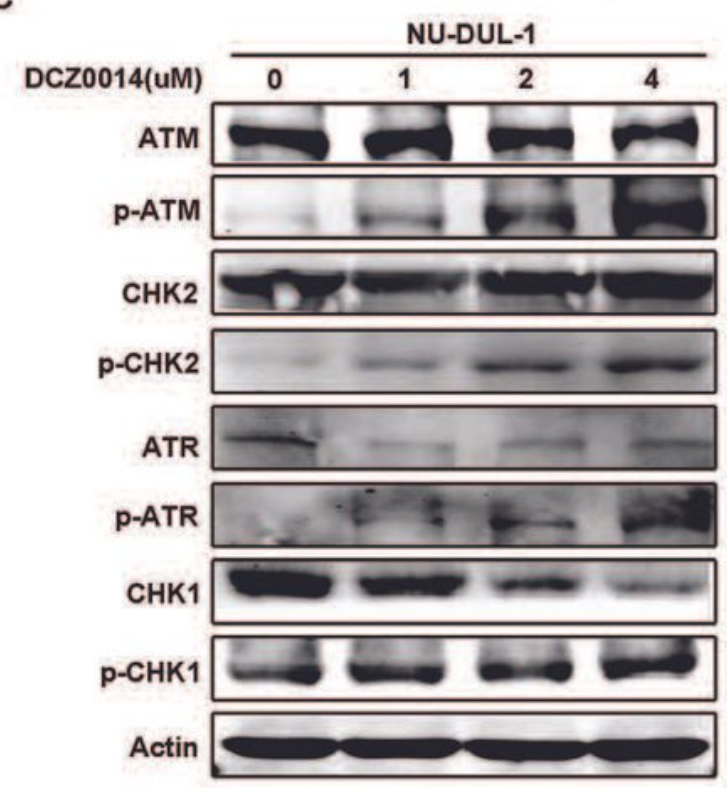

OCI-LY8
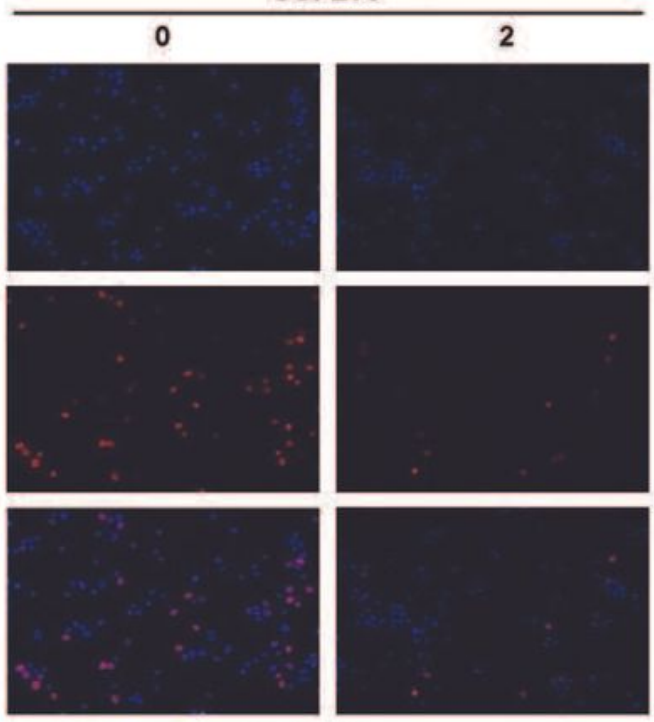

OCI-LY8

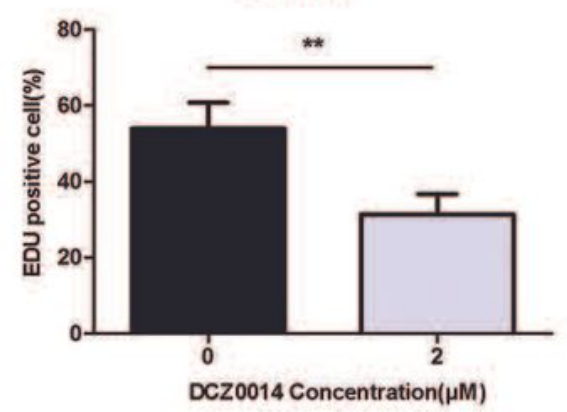

OCI-LY8

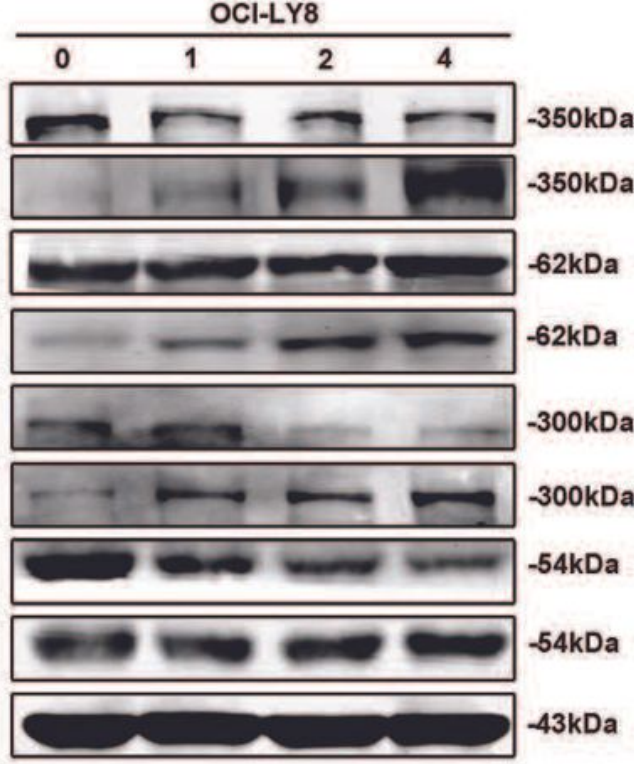

\section{Figure 4}

DCZ0014 inhibits DNA synthesis and aggravates DNA damage in DLBCL cells in vitro. (A) NU-DUL-1 cells and OCI-LY8 cells were treated with DCZ0014 (0 and $2 \mu \mathrm{M})$ for $48 \mathrm{~h}$, DNA synthesis was measured using an EDU kit and detected by confocal microscopy. Red indicates EDU-positive cells, (400x magnification).

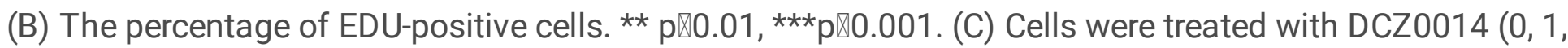


2 and $4 \mu \mathrm{M}$ ) for $48 \mathrm{~h}$, Western blot analysis was detected to the protein levels of ATM, phospho-ATM, ATR, phospho-ATR, CHK1, phospho-CHK1, CHK2 and phospho-CHK2.

A

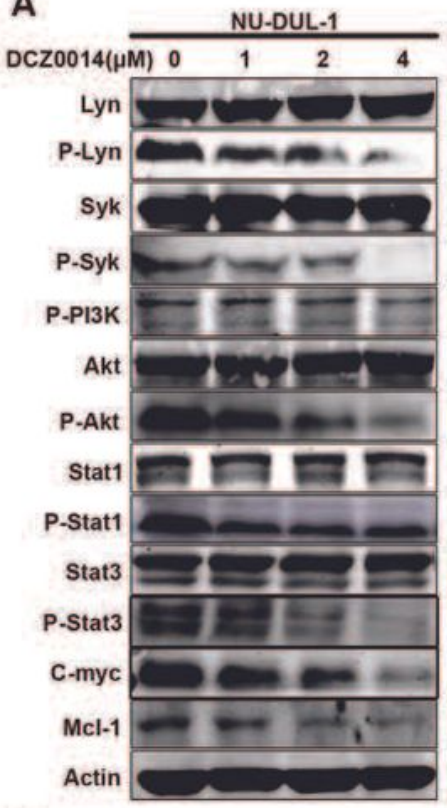

D $\operatorname{DCZ} 0014(\mu \mathrm{M}) 0$ SIRNA+2 2 OE+2 P.Lyn $=$ P.PI3K $\begin{aligned} & -85 \mathrm{kDa} \\ & -60 \mathrm{kDa}\end{aligned}$ Akt $\square-60 \mathrm{kDa}$

P.Akt

Stat1

P.Stat1 - -

P.Stat1 $2-\begin{aligned} & -91 \mathrm{kDa} \\ & -84 \mathrm{kDa}\end{aligned}$

Stat3 $20 \mathrm{cma}$

P.Stat3

$-79 \mathrm{kDa}$
$-60 \mathrm{dDa}$

C-myc

Actin

E

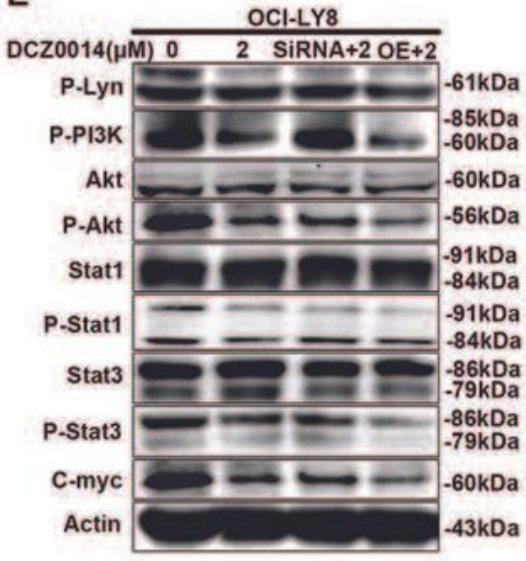
OCI-LY8
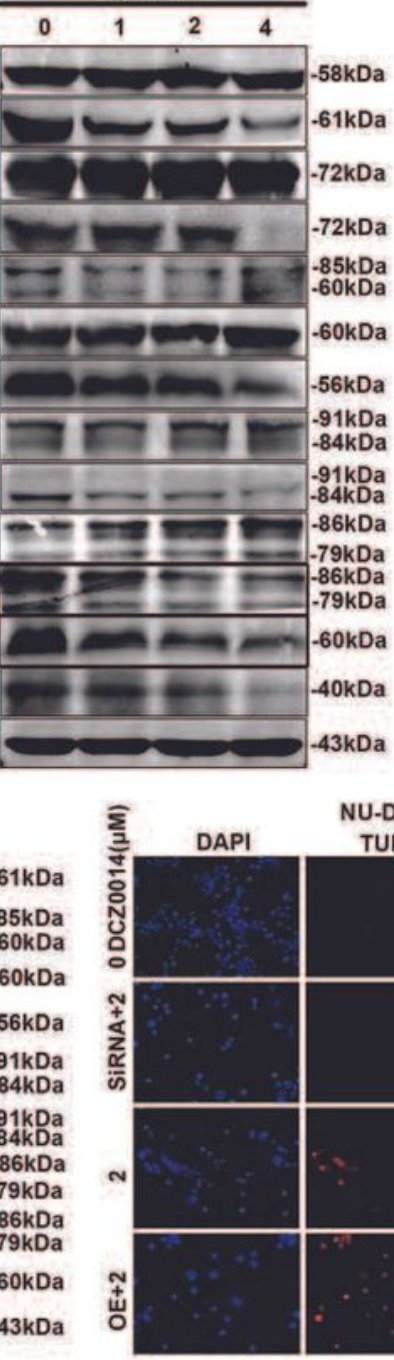

NU-DUL-1
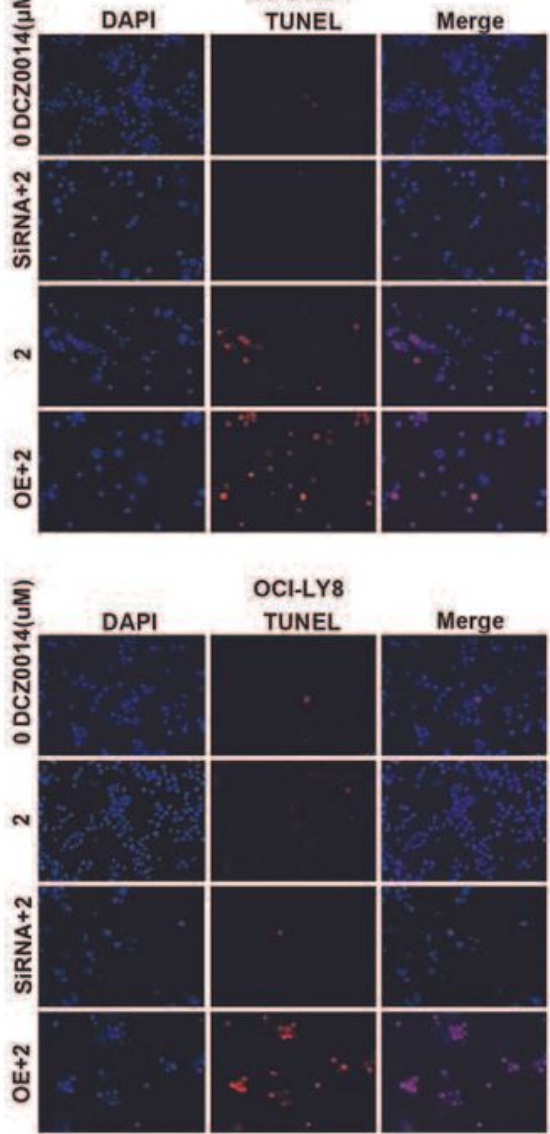

C
B
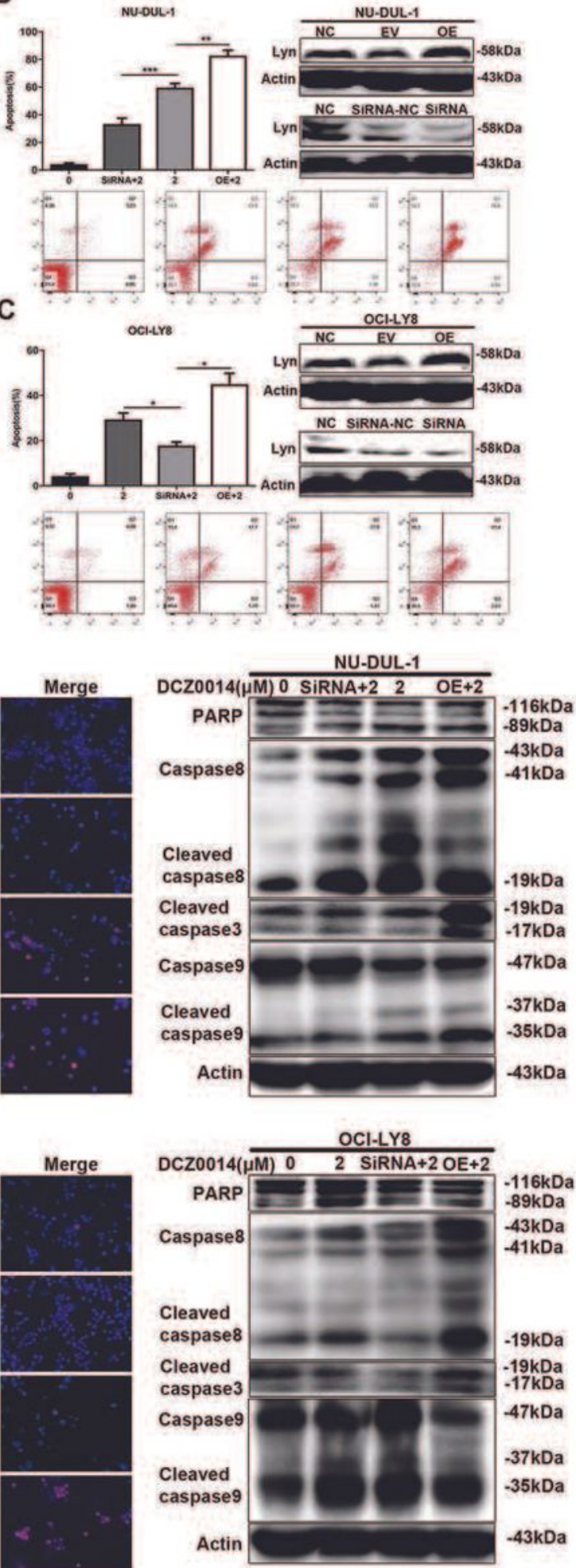

Figure 5

DCZ0014 inhibits Lyn/Syk in B cell receptor signaling pathway. (A) Cells were treated with DCZ0014 (0, 1, 2 and $4 \mu \mathrm{M})$ for $48 \mathrm{~h}$, Western blot analysis was detected to the protein levels of Lyn, phospho-Lyn, Syk, phospho-Syk, phospho-PI3K, AKT, phospho-AKT, Stat1, phospho-Stat1, Stat3, phospho-Stat3, C-myc, Mcl- 
1. (B-C) NU-DUL-1 and OCl-LY8 cells were transfected with Lyn siRNA, overexpression (Lyn) lentivirus or negative-control siRNA, respectively. The protein levels of Lyn and Actin were analyzed by western blot. And the transfected cells were treated with $2 \mu \mathrm{M}$ DCZ0014 for $48 \mathrm{~h}$, apoptosis was detected by Annexin-

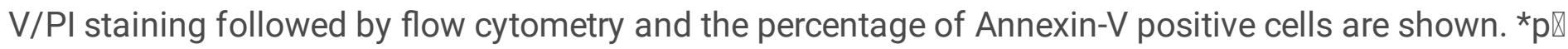
$0.05, * \star p \otimes 0.01, * \star * p \otimes 0.001$. (D-E) Western blot analysis was detected to the protein levels of Cleavedcaspase 3, 8, caspase 9, PARP. And the related of proteins levels in the Lyn/Syk B cell receptor signaling pathway and apoptosis analyzed by TUNEL assay. Red indicates TUNEL-positive cells, (400x magnification). 
A

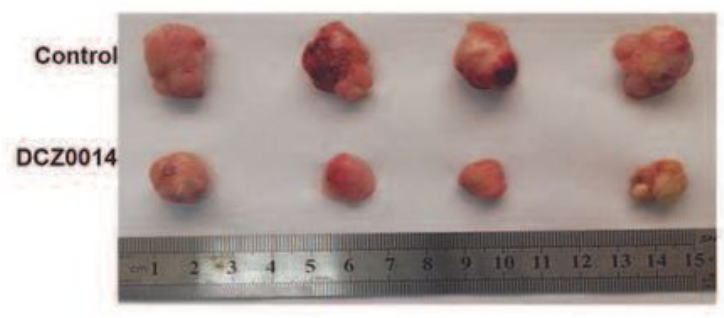

C

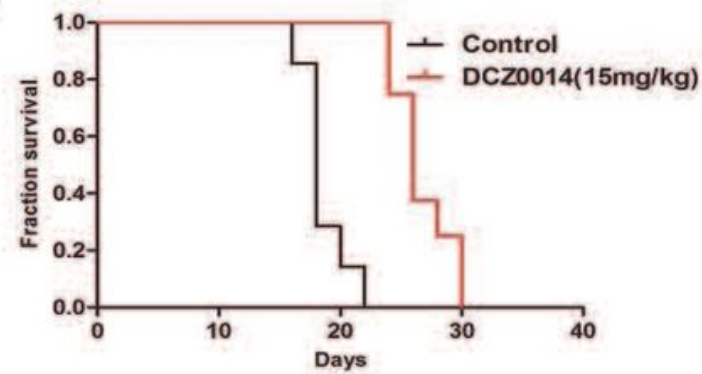

D

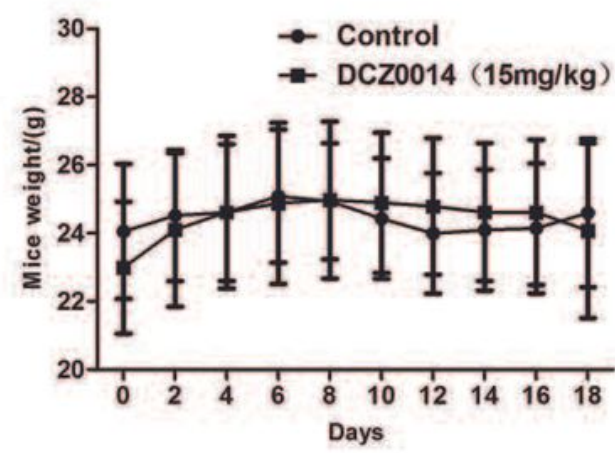

B
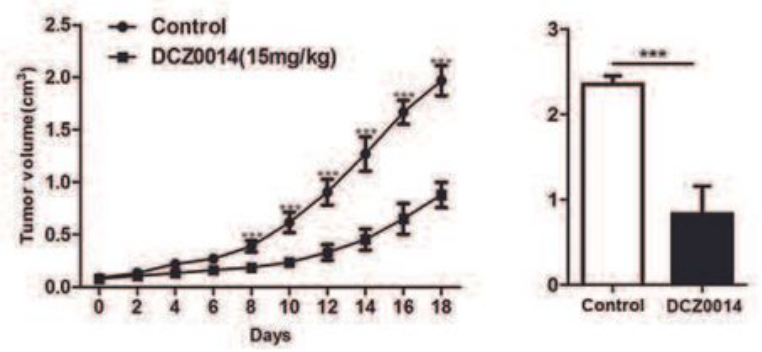

$\mathbf{E}$

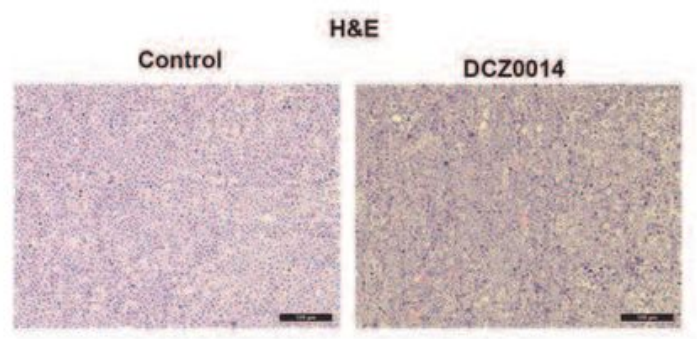

F

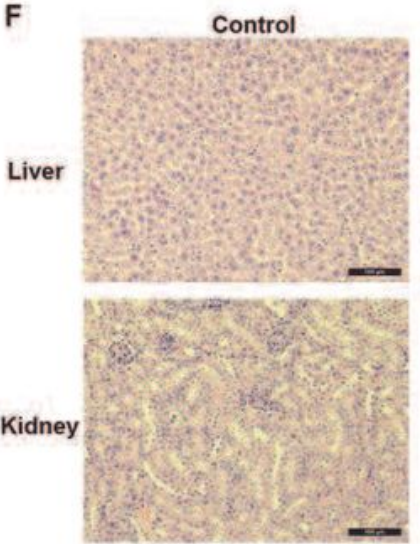

DCZ0014

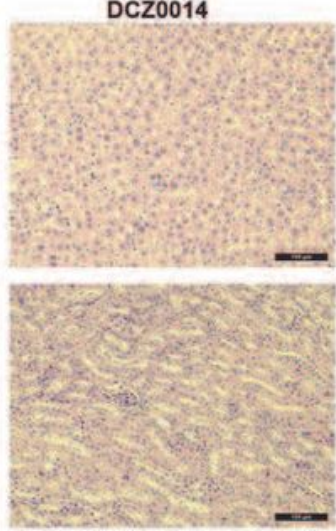

Ki67
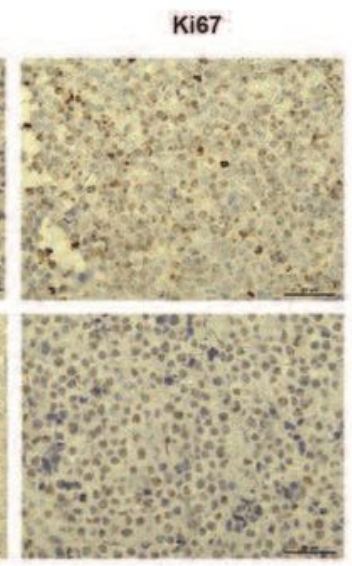

\section{Figure 6}

G

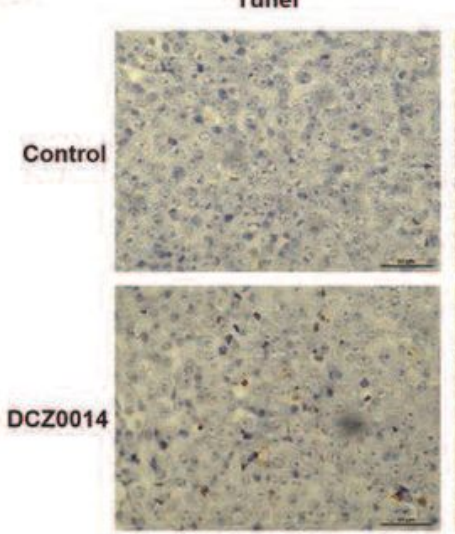

Cleaved-caspase 3
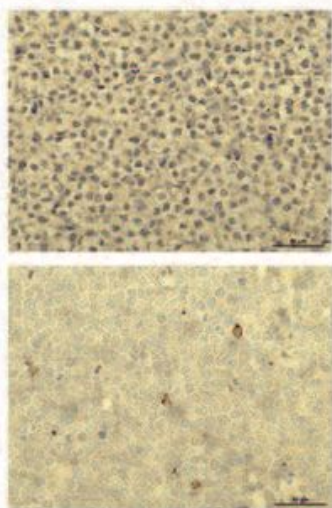

DCZ0014 inhibits tumor growth in a DLBCL xenograft model in vivo. Five-week-old male BALB/c nude mice were injected with OCl-LY8 cells $(2.5 \times 106)$. The mice were treated with vehicle or $15 \mathrm{mg} / \mathrm{kg}$ DCZ0014 every day for a total of 18 days via intraperitoneal injection after tumor formation. Tumor size and mouse body weight were measured every other daygroup; $n=4$ mice/group. (A) Tumors sample appearance. (B) Tumor volume was measured every other day for 18 days, $* \star * P \otimes 0.001$. The tumor weight 
was measured at 18 days. (C) The survival time of the mice. ${ }^{\star} \star \mathrm{P} \otimes 0.001$. (D) Mouse weight was measured every other day for 18 days. Hematoxylin and eosin (H\&E) staining of tumor tissues (E) and liver/kidney (F) after DCZ0014 treatment (200x magnification). (G) Immunohistochemical staining of Ki-67 and cleaved-caspase 3 and TUNEL staining to detect cell proliferation and cell apoptosis in vivo after DCZ0014 treatment (400x magnification).

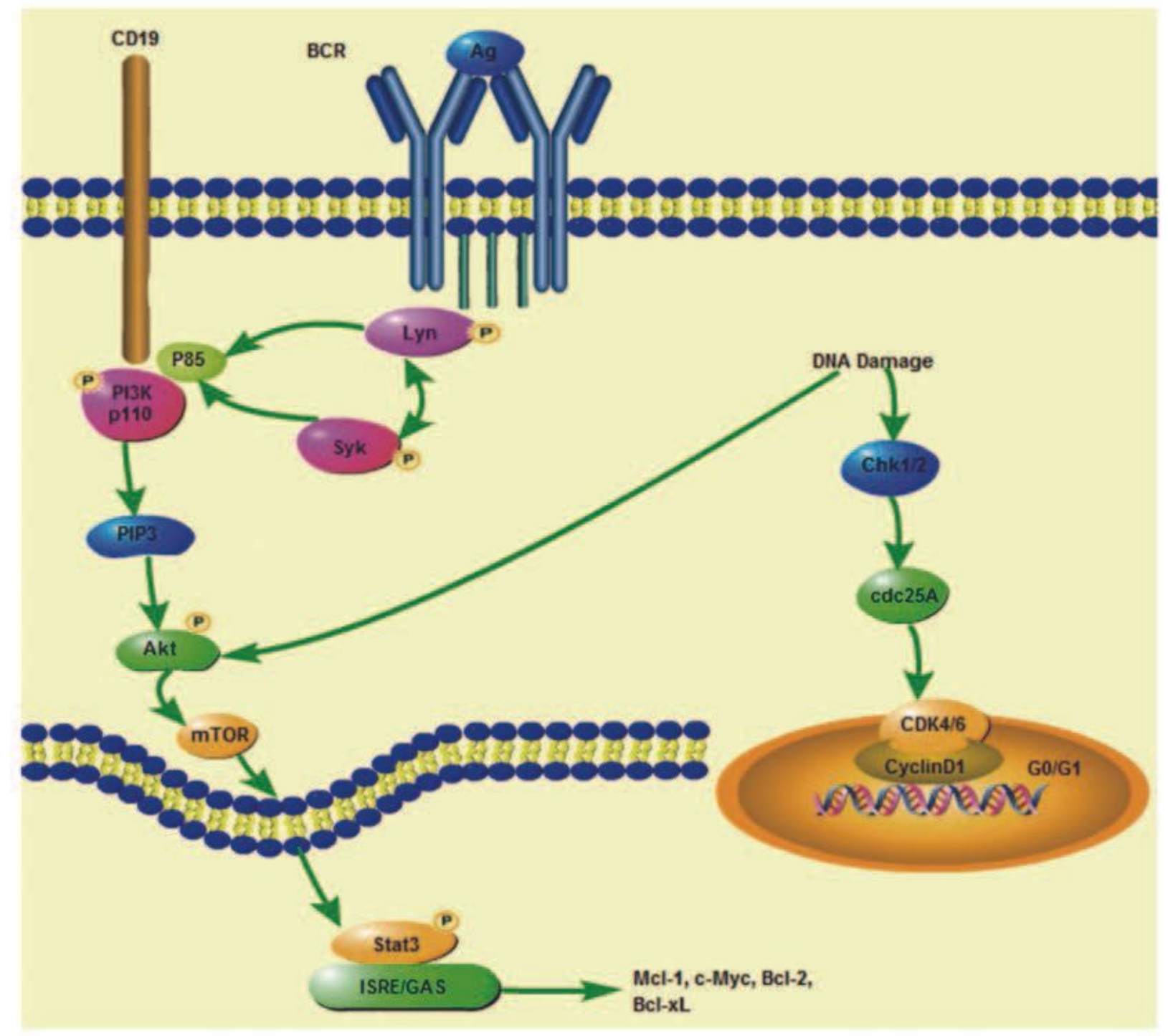

\section{Figure 7}

The signal transduction pathway that DCZ0014 induced in cell apoptosis of DLBCL cells. 